ARTICLE

https://doi.org/10.1038/s41467-019-09791-w

\title{
Na-doped ruthenium perovskite electrocatalysts with improved oxygen evolution activity and durability in acidic media
}

María Retuerto (10 1, Laura Pascual2 ${ }^{2}$, Federico Calle-Vallejo ${ }^{3}$, Pilar Ferrer ${ }^{4}$, Diego Gianolio (1) 4, Amaru González Pereira ${ }^{1}$ Álvaro García ${ }^{1}$, Jorge Torrero ${ }^{1}$, María Teresa Fernández-Díaz ${ }^{5}$, Peter Bencok ${ }^{4}$, Miguel A. Peña (1) ${ }^{1}$, José Luis G. Fierro ${ }^{1} \&$ Sergio Rojas ${ }^{1}$

The design of active and durable catalysts for the $\mathrm{H}_{2} \mathrm{O} / \mathrm{O}_{2}$ interconversion is one of the major challenges of electrocatalysis for renewable energy. The oxygen evolution reaction (OER) is catalyzed by $\mathrm{SrRuO}_{3}$ with low potentials (ca. $1.35 \mathrm{~V}_{\mathrm{RHE}}$ ), but the catalyst's durability is insufficient. Here we show that Na doping enhances both activity and durability in acid media. DFT reveals that whereas $\mathrm{SrRuO}_{3}$ binds reaction intermediates too strongly, $\mathrm{Na}$ doping of $\sim 0.125$ leads to nearly optimal OER activity. Na doping increases the oxidation state of Ru, thereby displacing positively $\mathrm{O}$ p-band and Ru d-band centers, weakening Ru-adsorbate bonds. The enhanced durability of $\mathrm{Na}$-doped perovskites is concomitant with the stabilization of Ru centers with slightly higher oxidation states, higher dissolution potentials, lower surface energy and less distorted $\mathrm{RuO}_{6}$ octahedra. These results illustrate how high OER activity and durability can be simultaneously engineered by chemical doping of perovskites.

\footnotetext{
${ }^{1}$ Grupo de Energía y Química Sostenible, Instituto de Catálisis y Petroleoquímica, CSIC. C/ Marie Curie 2, 28049 Madrid, Spain. ${ }^{2}$ Instituto de Catálisis y Petroleoquímica, CSIC. C/ Marie Curie 2, 28049 Madrid, Spain. ${ }^{3}$ Departament de Ciència de Materials i Química Física \& Institut de Química Teòrica i Computacional (IQTCUB), Universitat de Barcelona, 08028 Barcelona, Spain. ${ }^{4}$ Diamond Light Source, Harwell Science and Innovation Campus, Chilton, Didcot OX11 ODE, UK. ${ }^{5}$ Institut Laue-Langevin, BP156X, F-38042 Grenoble, France. Correspondence and requests for materials should be addressed to M.R. (email: m.retuerto@csic.es) or to F.C-V. (email: f.calle.vallejo@ub.edu) or to S.R. (email: srojas@icp.csic.es)
} 
E lectrochemical technologies promise the efficient and versatile storage and use of renewable energy in cycles that do not generate harmful by-products ${ }^{1}$. Therefore, they are expected to become major players in the shift towards circular economy and energy systems, once their present problems are solved $^{2}$. For instance, the oxygen evolution reaction (OER) in which $\mathrm{H}_{2} \mathrm{O}$ is oxidized to $\mathrm{O}_{2}$ is crucial in electrolyzers and in the charging of metal-air batteries. To compensate the sluggish kinetics of the OER, high overpotentials are needed in practical applications, causing severe energy losses ${ }^{3}$. Ir-based materials are the state-of-the-art OER catalysts ${ }^{4,5}$, which owing to their high price and scarcity must be replaced to facilitate wider implementation of electrolyzers. Functional oxides such as perovskites are promising OER electrocatalysts, especially in alkaline media $^{6-10}$. Recently, high OER activities in alkaline electrolyte have been reported for thin films of $\mathrm{SrRuO}_{3}\left(0.1 \mathrm{~mA} \mathrm{~cm}^{-2}\right.$ at $1.33 \mathrm{~V}$ vs. RHE $)^{11}$. However, this material loses its activity after only two cycles. The lack of stability of Ru-based oxides appears to be related to the transformation of $\mathrm{Ru}^{4+}$ into $\mathrm{Ru}^{>4+}$ at high voltages (above 1.3-1.4 V) ${ }^{12,13}$ leading to the decomposition of the perovskite, which starts with $\mathrm{Sr}$ dissolution followed by the collapse of the mixed-oxide structure ${ }^{11}$. Very few examples of perovskites with high OER activity in acid exist. For instance, $\mathrm{SrRuO}_{3}$ nanopowders ${ }^{13}$ (initial $30 \mathrm{Ag}^{-1}$ at $1.37 \mathrm{~V}$ ), bulk iridiumbased double perovskites ${ }^{14}\left(10 \mathrm{mAcm}^{-2}\right.$ oxide at $\left.1.6 \mathrm{~V}\right), \mathrm{SrIrO}_{3} /$ $\mathrm{IrO}_{x}$ thin films ${ }^{15}\left(10 \mathrm{~mA} \mathrm{~cm}^{-2}\right.$ oxide at $\left.1.5 \mathrm{~V}\right)$. On the other hand, Ir, $\mathrm{Ru}, \mathrm{IrO}_{2}$ and $\mathrm{RuO}_{2}$ nanoparticles show high OER activity, Ru-based compounds present $2 \mathrm{~mA} \mathrm{~cm}^{-2}$ at $1.42 \mathrm{~V}$ and $\mathrm{IrO}_{x} \sim 10 \mathrm{~mA} \mathrm{~cm}^{-2}$ oxide at $1.52 \mathrm{~V}^{16,17}$. A grand challenge in electrocatalysis is, therefore, the design of perovskites with high and long-lasting OER activities in acid media.

Here we show that the OER activity and durability in acid of bulk $\mathrm{SrRuO}_{3}$ can be enhanced by $\mathrm{Na}^{+}$doping in the $\mathrm{Sr}^{2+}$ position. Thus, $\mathrm{Sr}_{0.95} \mathrm{Na}_{0.05} \mathrm{RuO}_{3}$ and $\mathrm{S}_{0.90} \mathrm{Na}_{0.10} \mathrm{RuO}_{3}$ exhibit very high specific OER activity, with a potential of $\sim 1.35 \mathrm{~V}$ (an overpotential of only $120 \mathrm{mV}$ ) at $0.5 \mathrm{~mA} \mathrm{~cm}^{-2}$ geo. Thorough physical and chemical studies of fresh and used perovskites reveal that substituting $\mathrm{Sr}$ by $\mathrm{Na}$ increases the stability of the perovskite structure, thus preventing deactivation during repeated cycling. This result is also supported by DFT, demonstrating lower surface energy and higher dissolution potentials for $\mathrm{Na}$-doped perovskites, which slows down the collapse of the perovskite structure.

\section{Results and discussion}

Composition, structure, and oxidation state. $\mathrm{SrRuO}_{3}$, $\mathrm{Sr}_{0.95} \mathrm{Na}_{0.05} \mathrm{RuO}_{3}$, and $\mathrm{Sr}_{0.90} \mathrm{Na}_{0.10} \mathrm{RuO}_{3}$ were prepared by sol-gel chemistry followed by thermal treatment in air, with an increase of the synthesis temperature as the content of $\mathrm{Na}$ increases (Methods section). The chemical composition of the samples was analyzed by PND, EDX, and ICP-OES (see Supplementary Note 1). Sr and Na contents of Sr0.936(7)/Na0.064(7) for $x=0.05$ and $\mathrm{Sr} 0.906(1) / \mathrm{Na} 0.094(1)$ for $x=0.10$ were obtained from PND. As discussed below, STEM-EDX mappings confirm that $\mathrm{Na}$ is homogeneously distributed into the perovskites. Attempts to introduce higher $\mathrm{Na}$, e.g., $\mathrm{Sr}_{0.85} \mathrm{Na}_{0.15} \mathrm{RuO}_{3}$ and $\mathrm{Sr}_{0.80} \mathrm{Na}_{0.20} \mathrm{RuO}_{3}$ were not successful. Thus, the actual content of $\mathrm{Na}$ in $\mathrm{Sr}_{0.85} \mathrm{Na}_{0.15} \mathrm{RuO}_{3}$ is $x \sim 0.08$, lower than the nominal value. This is probably because the higher synthesis temperature results in a partial evaporation of $\mathrm{Na}$. In fact, $\mathrm{Sr}_{0.80} \mathrm{Na}_{0.20} \mathrm{RuO}_{3}$ could not be prepared. For what is worth, characterization details for $\mathrm{Sr}_{0.85} \mathrm{Na}_{0.15} \mathrm{RuO}_{3}$ are presented in the Supplementary Note 2, Supplementary Fig. 1, and Supplementary Tables 1, 2 and 3.

$\mathrm{SrRuO}_{3}, \mathrm{Sr}_{0.95} \mathrm{Na}_{0.05} \mathrm{RuO}_{3}$, and $\mathrm{Sr}_{0.90} \mathrm{Na}_{0.10} \mathrm{RuO}_{3}$ display perovskite structure (see x-ray diffraction (XRD) patterns, Supplementary Fig. 2). The cell volume decreases upon $\mathrm{Na}$ incorporation (Inset of
Supplementary Fig. 2), justified by the smaller radii of $\mathrm{Na}^{+}$and $\mathrm{Ru}^{>4+}$ compared to $\mathrm{Sr}^{2+}$ and $\mathrm{Ru}^{4+}$, respectively ${ }^{18}$, and in good agreement with previous literature ${ }^{19}$ and our DFT calculations (see the Computational Methods section).

Powder neutron diffraction (PND) is the most suitable technique to assess oxygen vacancies, atomic occupancies, structural distortions, atomic positions, bond distances, and angles of oxides. $\mathrm{SrRuO}_{3}$ and $\mathrm{Na}$-doped samples adopt an orthorhombic perovskite structure with space group Pbnm, with $\mathrm{Sr}^{2+} / \mathrm{Na}^{+}$located randomly at $\mathrm{A}$ sites and $\mathrm{Ru}^{\mathrm{n}+}$ at $\mathrm{B}$ sites, as previously reported ${ }^{19}$. Fig. 1a shows good agreement between calculated and experimental PND data. The structural results obtained from PND Rietveld refinements are shown in Supplementary Table 4. First, we verified the lack of vacancies in A-sites and then we refined the $\mathrm{Na}$ occupancy into Sr-sites. The refined $\mathrm{Na}$ contents are close to the nominal values, in agreement with the values obtained by ICP-OES and the cell volume observed with XRD (Supplementary Note 1, Supplementary Fig. 2, and Supplementary Table 5). Figure $1 \mathrm{~b}$ and Supplementary Fig. 3 show the $\mathrm{Ru}-\mathrm{O}$ distances on the $\mathrm{RuO}_{6}$ octahedra. $\mathrm{RuO}_{6}$ octahedra in $\mathrm{SrRuO}_{3}$ are more distorted than in $\mathrm{Sr}_{0.95} \mathrm{Na}_{0.05} \mathrm{RuO}_{3}$ and $\mathrm{Sr}_{0.90} \mathrm{Na}_{0.10} \mathrm{RuO}_{3}$, with large $a b$ in-plane deformation, shortened Ru-O1 distances (1.950(2) $\AA$ ) and elongated Ru-O1 distances $(2.006(2) \AA)$. Note that this deformation has been previously reported for $\mathrm{SrRuO}_{3}{ }^{20,21}$. Conversely, $\mathrm{Na}$-doped samples show very similar $\mathrm{Ru}-\mathrm{O}$ distances (of ca. $1.98 \AA$ ) on the $\mathrm{RuO}_{6}$ octahedra, indicating that the octahedra are regular and not distorted as in $\mathrm{SrRuO}_{3}$ (Fig. 1c). The different octahedra distortion of $\mathrm{SrRuO}_{3}$ and Na-doped samples could be a consequence of the slight change of $\mathrm{Ru}$ oxidation states in $\mathrm{Na}$ doped perovskites, as confirmed from XAS (see below). $\mathrm{SrRuO}_{3}$ contains $\mathrm{Ru}^{4+}$ cations $\left(4 d^{4}\right)$ with relatively extended $d$ orbitals.

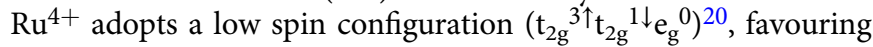
Jahn-Teller distortions that split the threefold $t_{2 g}$ into one lower $d_{x z}$ orbital and two higher $d_{y z}$ and $d_{x y}$ orbitals. Such Jahn-Teller distortion causes the aforementioned elongated and shortened $\mathrm{Ru}-\mathrm{O}$ distances. However, upon $\mathrm{Na}$ doping, a slight overoxidation to $\mathrm{Ru}^{>4+}$ occurs resulting in the partial elimination of the fourth spin of the $t_{2 g}$, which could prevent the Jahn-Teller effect (or produce a switch to a high spin configuration) resulting in more regular octahedra. In addition, the higher temperatures used for the synthesis of the Na-doped perovskites could affect the different distortions. The implications of the actual structure of the perovskite for the OER performance are discussed below.

PND results also show that, within the error, the perovskites lack cationic and oxygen vacancies (Supplementary Table 4). Further experimental evidences of the absence of short- or longrange ordered oxygen vacancies were attained from HRTEM and selected area electron diffraction (SAED) patterns (Supplementary Fig. 4) in which diffraction spots for stoichiometric perovskites are the only ones observed. Moreover, DFT reveals large energies of formation of oxygen vacancies (bulk and surface), confirming the unlikely formation of such vacancies (Supplementary Note 3, Supplementary Fig. 5, and Supplementary Table 6). The lack of oxygen vacancies implies that $\mathrm{Na}$ incorporation is compensated by partial oxidation of $\mathrm{Ru}$ atoms.

The effect of $\mathrm{Na}$ doping in the structure and oxidation state of $\mathrm{Ru}$ was analyzed by $\mathrm{x}$-ray absorption spectroscopy (XAS). We performed XAS in different energy ranges, soft and hard X-rays, to study the K-edge of $\mathrm{Na}$, and the K-edges and $\mathrm{M}_{2,3}$-edges of $\mathrm{Ru}$. The spectra of the Na K-edge confirm the presence of $\mathrm{Na}$ in the Na-doped perovskites (Supplementary Fig. 6). The strong overlap with the $\mathrm{Sr}$ L-edge background signal prevents an accurate estimation of the actual $\mathrm{Na}$-content in each perovskite by this technique. In addition, the analysis of the $\mathrm{Ru} \mathrm{K}$-edge further confirms the incorporation of $\mathrm{Na}$ into the perovskites 

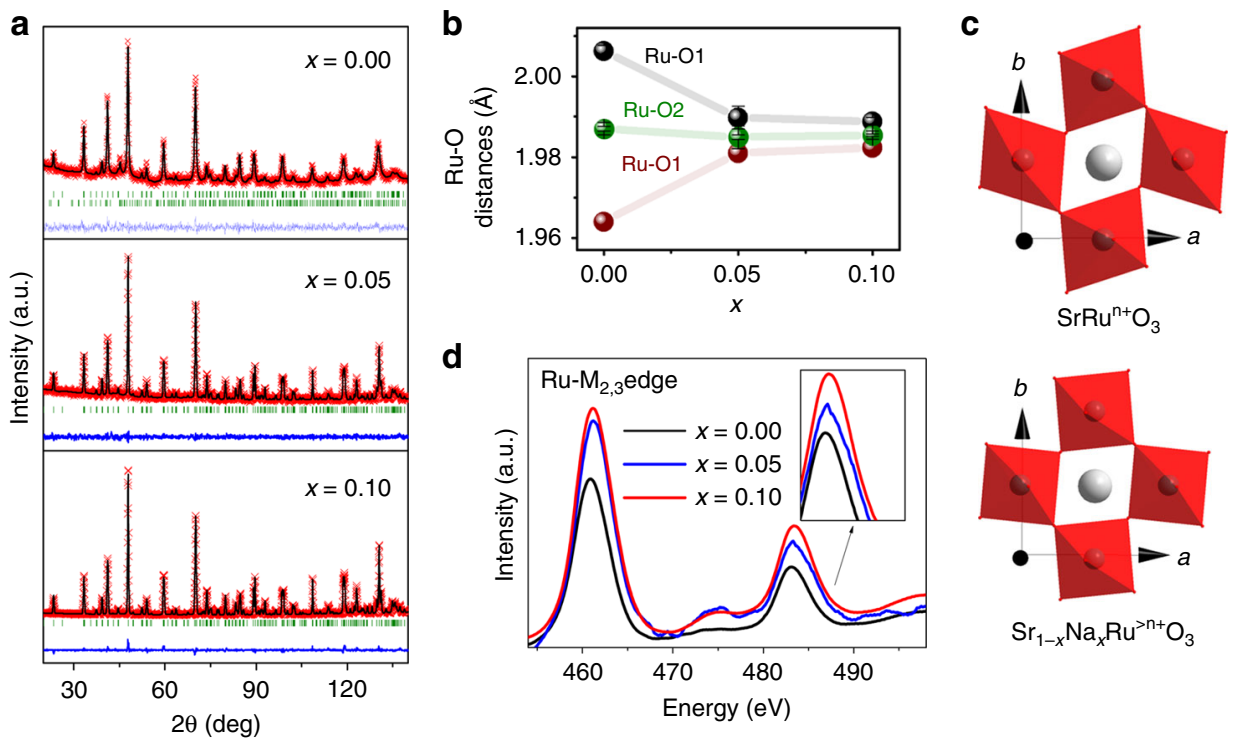

Fig. 1 Crystallographic study of $\mathrm{SrRuO}_{3}, \mathrm{Sr}_{0.95} \mathrm{Na}_{0.05} \mathrm{RuO}_{3}$ and $\mathrm{Sr}_{0.90} \mathrm{Na}_{0.10} \mathrm{RuO}_{3}$. a Structural Rietveld refinements from PND data at room temperature. Observed (crosses), calculated (full line) and difference (bottom) profiles. Bragg lines correspond to the crystallographic structures. The second Bragg line on $\mathrm{SrRuO}_{3}$ corresponds to $\sim 6 \%$ of $\mathrm{Sr}_{4} \mathrm{Ru}_{2} \mathrm{O}_{3}$. b Ruthenium-oxygen distances in the $\mathrm{RuO}_{6}$ octahedra. c Octahedral distortion in $\mathrm{SrRuO} \mathrm{O}_{3}$ (exaggerated to facilitate its visualization) compared to Na-doped samples. d Ru M 2,3 -edge XANES spectra for $\mathrm{SrRuO}_{3}$ (black), $\mathrm{Sr}_{0.95} \mathrm{Na}_{0.05} \mathrm{RuO}_{3}$ (blue) and $\mathrm{Sr}_{0.90} \mathrm{Na}_{0.10} \mathrm{RuO}_{3}$ (red). The inset shows the $\sim 461 \mathrm{eV}$ region with $\mathrm{SrRuO}_{3}$ spectrum displaced upward for clarity

(Supplementary Note 4, and Supplementary Figs. 6b and 7). The Fourier transforms from the Ru K-edge EXAFS signals (phase non-corrected) shown in Supplementary Fig. $6 \mathrm{~b}$ reveal that the signals for $\mathrm{SrRuO}_{3}$ are less intense than the ones of the Na-doped samples, indicating a higher distortion of the $\mathrm{RuO}_{6}$ octahedra in $\mathrm{SrRuO}_{3}$, in agreement with PND data.

The oxidation state of $\mathrm{Ru}$ was determined by the analysis of the $\mathrm{Ru} \mathrm{M} \mathrm{M}_{2,3}$-edge. This edge is associated with the promotion of $3 \mathrm{p}$ to $4 \mathrm{~d}$ orbitals in $\mathrm{Ru}$ and is more sensitive to changes in the d-states than the K-edge. As observed in Fig. 1d, the XANES signals of $\mathrm{Sr}_{0.95} \mathrm{Na}_{0.05} \mathrm{RuO}_{3}$ and $\mathrm{Sr}_{0.90} \mathrm{Na}_{0.10} \mathrm{RuO}_{3}$ appear at higher energies than $\mathrm{SrRuO}_{3}$. In addition, a slight broadening to the low energy region of the peaks of the $\mathrm{Na}$-doped is observed. Both features are indicative of a higher oxidation state of $\mathrm{Ru}$ atoms in the $\mathrm{Na}$ containing perovskites ${ }^{22}$.

Electrochemical performance. The OER activity of $\mathrm{SrRuO}_{3}$, $\mathrm{Sr}_{0.95} \mathrm{Na}_{0.05} \mathrm{RuO}_{3}$, and $\mathrm{Sr}_{0.90} \mathrm{Na}_{0.10} \mathrm{RuO}_{3}$ was evaluated in $\mathrm{O}_{2^{-}}$ saturated $0.1 \mathrm{M} \mathrm{HClO}_{4}$ at $1600 \mathrm{rpm}$. The catalysts were deposited onto a glassy carbon electrode using an ink (Methods section). High surface area carbon was mixed with the perovskites (1:5 in weight) to improve the conductivity ${ }^{23}$.

Figure 2a shows the current densities ( $j$ ) normalized by the geometric area $\left(0.196 \mathrm{~cm}^{2}\right)$. Na-doped samples present similar current densities than $\mathrm{SrRuO}_{3}$ in the whole polarization range. The potential to reach a current density of $j=0.5 \mathrm{~mA} \mathrm{~cm}^{-2}$ geo is $\sim 1.35 \mathrm{~V}$ for the three samples, equivalent to an overpotential $(\eta)$ of only $120 \mathrm{mV}$. In comparison, the potential to achieve $j=$ $0.5 \mathrm{mAcm}^{-2}$ geo with $\mathrm{RuO}_{2}$ is $\sim 1.4 \mathrm{~V}^{16}$. The low overpotentials of $\mathrm{Sr}_{1-x} \mathrm{Na}_{x} \mathrm{RuO}_{3}$ are in line with the potential reported to achieve the same current density for thin films of $\mathrm{SrRuO}_{3}$ in alkaline media of 1.35-1.40 V (the actual value depending on the exposed plane $)^{11}$ and $\mathrm{Ru}$ metal in acid media $(\sim 1.32 \mathrm{~V})^{5}$. However, the latter catalysts transform into $\mathrm{RuO}_{x}$ already in the first reaction cycle losing most of their initial activity.

As reported in Supplementary Table 7, the Na-containing perovskites have larger particle sizes than $\mathrm{SrRuO}_{3}$. Although it is well accepted that the OER is a structure sensitive reaction, the actual effect of particle size is not clear. Krtil et al. ${ }^{24}$ reported that the onset for the oxygen evolution current is particle-size independent for $\mathrm{RuO}_{2}$ electrodes, but not for $\mathrm{Ru}_{0.8} \mathrm{Co}_{0.2} \mathrm{O}_{2-x}$. By contrast, Reier et al. ${ }^{25}$ reported that nanosized $\mathrm{Pt}, \mathrm{Ru}$, and Ir particles are more active than the corresponding bulk phases. Shao-Horn et al. ${ }^{26}$ found that the OER activity of $\mathrm{La}_{0.1}\left(\mathrm{Ba}_{0.5} \mathrm{Sr}_{0.5}\right)_{0.9} \mathrm{Co}_{0.8} \mathrm{Fe}_{0.2} \mathrm{O}_{3-\delta}$ perovskites does not follow a linear relationship with particle size, and Schmidt et al. ${ }^{27}$ indicated that the OER activity of $\mathrm{IrO}_{x}$ does not increase monotonically with the surface area and suggest that morphology can also play a key role. In this sense, Matsumoto et al. ${ }^{28,29}$ reported that OER activity of mixed oxides could be related to the exposed facets, but failed to identify the most active ones. Recently, by using thin films of $\mathrm{SrRuO}_{3}$, Markovic et al. ${ }^{11}$ reported that the (111) face is more active for the OER than (001). Shao-Horn et al. ${ }^{30}$ reported that (100) facets of $\mathrm{RuO}_{2}$ and $\mathrm{IrO}_{2}$ are more active in alkaline media than the thermodynamically stable (110). We have found no evidences of preferential surface termination in our samples, but as shown in Supplementary Table 7, particle size increases with $\mathrm{Na}$ doping. Therefore, and in order to assess intrinsic catalytic activities $\left(i_{s}\right)$, the OER currents have been normalized to the oxide surface area, using BET, mass-specific surface areas $\left(A_{S}\right)^{31}$, or electrochemical surface areas (ECSA);32,33 see Supplementary Note 5 and Supplementary Table 7. The promotional effect of $\mathrm{Na}$ doping is clearly observed in Supplementary Fig. 8, where $\mathrm{i}_{\mathrm{s}}$ follows the order $\mathrm{Sr}_{0.90} \mathrm{Na}_{0.10} \mathrm{RuO}_{3} \geq \mathrm{Sr}_{0.95} \mathrm{Na}_{0.05} \mathrm{RuO}_{3}>\mathrm{SrRuO}_{3}$. Recently, a protocol to account for the effect of bubbles in the active area during the OER has been reported ${ }^{34}$.

In Fig. $2 b$ we report the OER intrinsic activities vs. $A_{S}$. Nadoped perovskites show higher current densities than $\mathrm{SrRuO}_{3}$. For comparison, the potential to reach $10 \mathrm{~mA} \mathrm{~cm}^{-2}$ oxide with $\mathrm{Sr}_{0.90} \mathrm{Na}_{0.10} \mathrm{RuO}_{3}$ is $1.4 \mathrm{~V}$; less positive than those reported for state-of-the-art perovskites of $1.5 \mathrm{~V}$ for $\mathrm{SrIrO}_{3} / \mathrm{IrO}_{\mathrm{x}}{ }^{15}$ or $1.5-1.6$ $\mathrm{V}$ for Ir-based double perovskites ${ }^{14}$. The actual production of $\mathrm{O}_{2}$ during the OER has been confirmed by using a RRDE (rotating ring disk electrode, see Supplementary Note 6 and Supplementary Fig. 9) and by following $\mathrm{O}_{2}$ evolution during the OER, using a mass spectrometer probe immersed in the electrolyte (Supplementary Note 7 and Supplementary Fig. 10). 

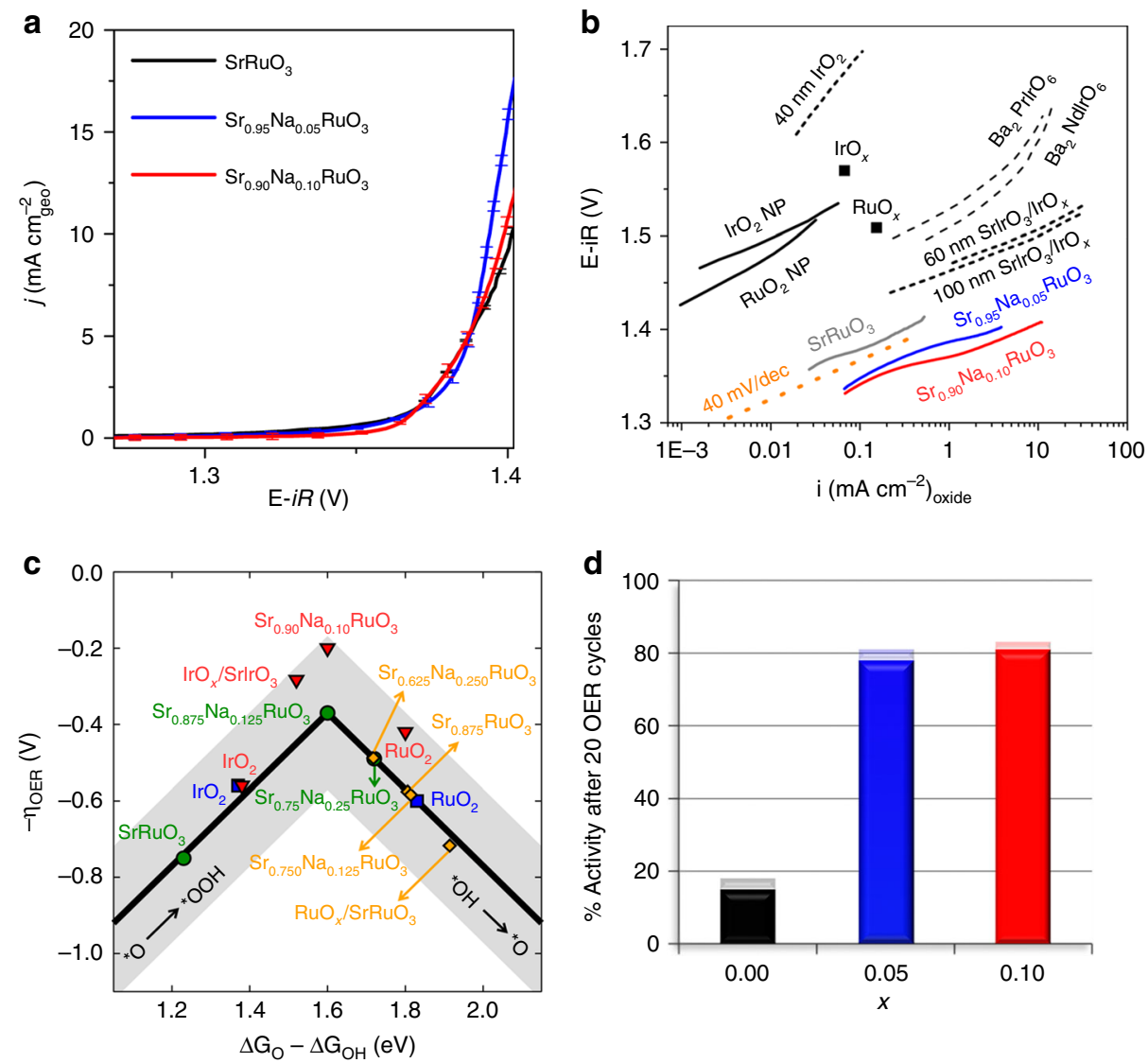

Fig. 2 OER activity and durability. a Current densities ( $j$ ) curves $\left(\mathrm{SrRuO}_{3}\right.$ (black), $\mathrm{Sr}_{0.95} \mathrm{Na}_{0.05} \mathrm{RuO}_{3}$ (blue) and $\mathrm{Sr}_{0.90} \mathrm{Na}_{0.10} \mathrm{RuO}_{3}$ (red)) including the relative standard deviation (RSD). b TAFEL plots compared to the intrinsic activities of selected OER catalysts in acidic media. The data are taken from ref. ${ }^{14,15}$. We represent the normalization using $A_{s}$. A line corresponding to a Tafel slope of $40 \mathrm{~mA} /$ decade (magenta dotted line) serves as a guide to the eye. c, OER Volcano-type activity plot. Data in green for $\mathrm{Sr}_{1-x} \mathrm{Na}_{x} \mathrm{RuO}_{3}$, orange (partially dissolved perovskites, see also Supplementary Fig. 14c) and RuO ${ }_{2}$ (blue) are from this study, data for $\mathrm{IrO}_{2}$ (blue) is from ref. 60. Data in red come from experiments (this work; refs. ${ }^{15,30}$ ), following the approach of Jaramillo and coworkers $^{36}$, which correlates DFT-calculated descriptors with experimental overpotentials at $1 \mathrm{~mA} / \mathrm{cm}^{2}$ oxide. Error bands of $\pm 0.2 \mathrm{~V}$ surround the lines to account for the accuracy of the calculations. $\mathbf{d}$ Percentage catalytic activity of $\mathrm{Sr}_{1-x} \mathrm{Na}_{x} \mathrm{RuO}_{3}$ after 20 cycles with respect to the initial activity, including RSD as shadow bars

Figure $2 \mathrm{~b}$ compares the Tafel plots of the intrinsic activities of the catalysts under study with the best catalysts in acid electrolyte reported in the literature. The initial activities of $\mathrm{Sr}_{1-x} \mathrm{Na}_{x} \mathrm{RuO}_{3}$ are higher than the ones reported for similar catalysts. Currents similar to Ir double perovskites or $\mathrm{SrIrO}_{3} / \mathrm{IrO}_{x}$ $\left(\sim 5-10 \mathrm{~mA} \mathrm{~cm}{ }^{-2} \text { oxide }\right)^{14,15}$ are achieved by $\mathrm{Sr}_{1-x} \mathrm{Na}_{x} \mathrm{RuO}_{3}$ at significantly lower overpotentials.

The catalytic activity enhancement of $\mathrm{SrRuO}_{3}$ upon Na doping is analyzed in Fig. $2 c$ using a DFT-based screening study in which the OER mechanism on all materials is assumed to proceed as: $\mathrm{H}_{2} \mathrm{O} \rightarrow{ }^{\star} \mathrm{OH} \rightarrow{ }^{\star} \mathrm{O} \rightarrow{ }^{\star} \mathrm{OOH} \rightarrow \mathrm{O}_{2}$. This analysis outlines clear activity trends, namely that progressive $\mathrm{Na}$ doping weakens the adsorption energies because the surface oxygen p-band center and the $\mathrm{Ru}$ d-band center are positively displaced (see Supplementary Note 8 and Supplementary Fig. 11) 35 . The combinatorial model in Supplementary Note 9 and Supplementary Figs. 12 and 13 shows that doping is beneficial for moderate $\mathrm{Na}$ doping $(0<x<0.125)$ but becomes deleterious at larger $\mathrm{Na}$ doping $(x>0.125)$; see Supplementary Figs. 12 and 13. Figure 2c shows that $\mathrm{Sr}_{0.875} \mathrm{Na}_{0.125} \mathrm{RuO}_{3}$ is at the top of the volcano and that its decomposition into $\mathrm{RuO}_{2}$ decreases the activity. The activity of various defective surfaces $\left(\mathrm{Sr}_{0.875} \mathrm{RuO}_{3}, \mathrm{Sr}_{0.750} \mathrm{Na}_{0.125} \mathrm{RuO}_{3}\right.$, and $\mathrm{Sr}_{0.625} \mathrm{Na}_{0.250} \mathrm{RuO}_{3}, \mathrm{RuO}_{\mathrm{x}} / \mathrm{SrRuO}_{3}$, see Supplementary Fig. 14c) is always lower than that of $\mathrm{Sr}_{0.875} \mathrm{Na}_{0.125} \mathrm{RuO}_{3}$ but generally higher than that of $\mathrm{RuO}_{2}$. These results show that as the pristine
Na-doped perovskite decomposes (via $\mathrm{Sr}$ dissolution, $\mathrm{Na}$ dissolution or both, see Supplementary Note 10 and Supplementary Figs. 14b and 15), the activity decreases until it reaches that of $\mathrm{RuO}_{2}$, in agreement with our durability experiments (see below).

Although there is no one-to-one connection between theoretical and experimental overpotentials (Fig. 2b, c); Jaramillo et al. ${ }^{36}$ noted that the two overpotentials agree well when the experimental ones are taken at a current density of $1 \mathrm{~mA} \cdot \mathrm{cm}^{-2}$ oxide. Thus, Fig. $2 c$ contains suitable data from the literature showing good agreement between theory and experiments and confirms the high activity of Na-doped $\mathrm{SrRuO}_{3}$. The differences between Fig. $2 \mathrm{~b}, \mathrm{c}$ are probably due to DFT-based errors ${ }^{37}$, which in view of their intrinsic nature (because they are present in all data), translate into error bands around the volcano lines in Fig. 2c. In particular, the use of scaling relations (Supplementary Fig. 14a) and GGA exchange-correlation functionals set those errors at approximately $\pm 0.2 \mathrm{eV}$ for adsorption energies $( \pm 0.2 \mathrm{~V}$ for (over) potentials). See Supplementary Notes 11 and 12 .

We stress here that screening analyses are not intended to elucidate the exact OER mechanism, which is the subject of different types of studies ${ }^{38}$, but rather to enable the simultaneous comparison of several different materials that clarify the role of $\mathrm{Na}$ incorporation and dissolution on the activity. Further discussion on this subject is provided in Supplementary Note 11. 
Note in passing that Govindarajan et al. ${ }^{39}$ recently proposed a descriptor called electrochemical-step symmetry index (ESSI) for OER catalysts (see Supplementary Note 11 and Supplementary Fig. 14b). Although the descriptor is based on the departures of OER reaction energies from the ideal value of $1.23 \mathrm{~V}$, it does not depend on scaling relations, unlike the volcano plot in Fig. 2c. The conclusions drawn using ESSI are analogous to those of Fig. 2c, which substantiates our analysis. Furthermore, the ESSI analysis in Supplementary Fig. 14b suggests that $\mathrm{Sr}_{0.875} \mathrm{Na}_{0.125} \mathrm{RuO}_{3}$ could be further improved by strengthening its ${ }^{\star} \mathrm{OH}$ adsorption energy by $0.16 \mathrm{eV}$.

Stability during OER. Durability is a major concern when considering the actual implementation of an active OER catalyst in an electrolyzer, especially in acid electrolyte. As observed in Fig. 2d, replacing Sr by $\mathrm{Na}$ significantly improves the catalyst's stability. After 20 consecutive cycles of reaction, $\mathrm{SrRuO}_{3}$ loses more than $85 \%$ of its initial activity. This is in line with the observation that $\mathrm{SrRuO}_{3}$ loses its activity after few cycles ${ }^{11,13}$. Remarkably, Na-doped perovskites only lose ca. $15 \%$ of their initial activity after 20 cycles. In other words, to lose $65 \%$ of initial activity, $\mathrm{SrRuO}_{3}$ needs only $\sim 7$ cycles while $\mathrm{Sr}_{0.90} \mathrm{Na}_{0.10} \mathrm{RuO}_{3}$ needs $\sim 80$ (Supplementary Note 13 and Supplementary Figs. 16 and 17). The voltammograms recorded during the OER (Supplementary Fig. 16) are in line with those of Ru-based perovskites $^{13}$. Contrary to what is observed for Ir-based perovskites ${ }^{40}$, features due to the formation of oxides $\left(\mathrm{RuO}_{\mathrm{x}}\right)$ are not observed in the capacitive region of the voltammograms, probably because the expected features for the oxides overlap with the current due to the $\mathrm{OER}^{13}$. We emphasize the durability obtained for $\mathrm{S}_{\mathrm{r} 0.95} \mathrm{Na}_{0.05} \mathrm{RuO}_{3}$ and $\mathrm{S}_{\mathrm{r} 0.90} \mathrm{Na}_{0.10} \mathrm{RuO}_{3}$, first because most mixed oxides are not stable in acid, so finding a catalyst with such high activity, low overpotential, and durability over several cycles is already a noteworthy result. Second, because the high activities obtained are only met by $\mathrm{Ru}$ or Ir metals, which are rather unstable ${ }^{41}$. For instance, Ru metal in acid media loses most of its activity after the first cycle of reaction and completely dissolves within the first 10 cycles, due to metal oxidation when the potential rises ${ }^{42}$. $\mathrm{RuO}_{2}$ also presents high OER activity but suffers from corrosion after the first cycle; it should be noted, however, that $\mathrm{RuO}_{2}$ 's performance for the OER is influenced by its morphology ${ }^{43}$. Finally, the number of perovskites reported as OER catalysts in acid is limited and those with high activity are $\mathrm{SrIrO}_{3}$ and $\mathrm{SrRuO}_{3}$. In $\mathrm{SrIrO}_{3}, \mathrm{Sr}$ dissolves after the first cycles and it is suggested that $\mathrm{IrO}_{x}$ oxides at the catalyst's surface are responsible for the catalytic activity ${ }^{15}$. In $\mathrm{SrRuO}_{3}, \mathrm{Sr}$ dissolves decreasing the activity dramatically ${ }^{11,13}$. Durability studies of powder $\mathrm{La}_{2} \mathrm{LiIrO}_{6}$ in acid and alkaline conditions concluded that during the $\mathrm{OER}, \mathrm{IrO}_{2}$ nanoparticles segregate to the perovskite surface, resulting in an oxidized surface with high OER activity ${ }^{40}$. In summary, most reports indicate that metal oxides are prone to severe degradation issues under oxygen evolution conditions ${ }^{11,44}$.

Evolution of structure and composition during OER. Insights into deactivation of representative $\mathrm{SrRuO}_{3}$ and $\mathrm{Sr}_{0.90} \mathrm{Na}_{0.10} \mathrm{RuO}_{3}$ were obtained by analyzing fresh and used samples (after 20 OER cycles) and from the evolution of the composition of the electrolyte after 10, 40, and 80 OER cycles by ICP-OES (see also Supplementary Note 14).

As observed from the micrographs in Fig. $3 \mathrm{a}, \mathrm{SrRuO}_{3}$ consists of particles between ca. 200 and $800 \mathrm{~nm}$ with perovskite structure, see HRTEM/Digital Diffraction Pattern (DDP) in Fig. 3b and HRTEM/SAED in Supplementary Fig. 4. STEM-EDX mappings (Fig. 3c) reveal a homogeneous distribution of $\mathrm{Sr}$ and $\mathrm{Ru}$ along the particle with an atomic $\mathrm{Sr} / \mathrm{Ru}$ ratio close to 1 . After 20 cycles
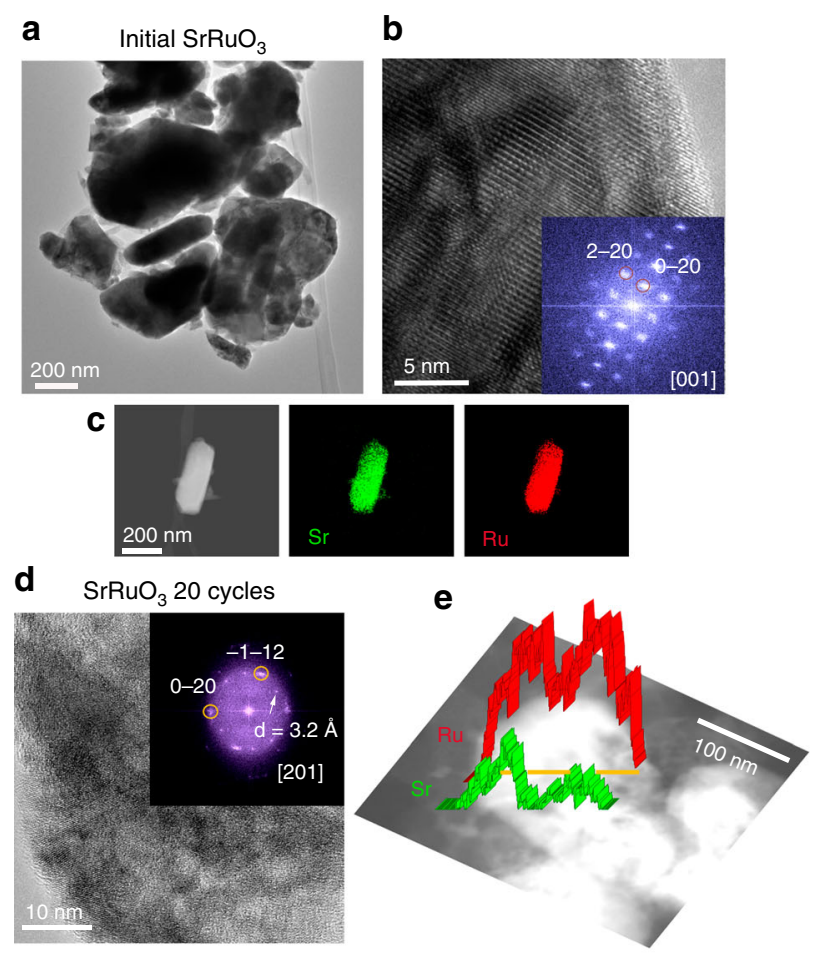

f EDX mapping of perovskite particles

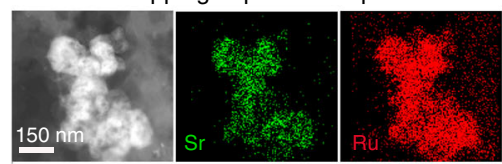

g

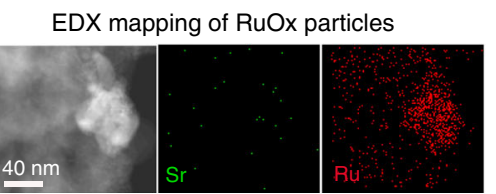

Fig. 3 Evolution of $\mathrm{SrRuO}_{3}$ during OER. a TEM, b HRTEM/DDP and c STEMEDX mapping of $\mathrm{SrRuO}_{3}$ perovskite before the OER reaction. d HRTEM/ DDP, e STEM-HAADF micrographs with the line scans, f STEM-EDX mappings of $\mathrm{SrRuO}_{3}$ after 20 OER cycles, $\mathbf{g}$ STEM-EDX mapping of a $\mathrm{RuO}_{x}$ particle segregated after 20 OER cycles

in the OER, significant changes in the morphology and composition of $\mathrm{SrRuO}_{3}$ are observed. Figure 3d shows a HRTEM/DDP image of used $\mathrm{SrRuO}_{3}$. The DDP shows spots that can be ascribed to two different phases: the original perovskite in the [201] zone axis and spots of $d=3.2 \AA$ attributed to the (110) interplanar distances in rutile $\mathrm{RuO}_{2}$. Compositional analyses of the used $\mathrm{SrRuO}_{3}$ (Fig. 3e-g) reveal the loss of $\mathrm{Sr}$ during the OER (voids are observed in the STEM image in Fig. 3e) leading to regions with high $(\sim 3) \mathrm{Ru} / \mathrm{Sr}$ ratio (Fig. 3e, f) along with segregated $\mathrm{RuO}_{x}$ particles as shown in Fig. 3g. This observation is consistent with the analysis of the composition of the electrolyte during OER with $\mathrm{SrRuO}_{3}$. As shown in Supplementary Fig. 17, the concentration of $\mathrm{Sr}$ in the electrolyte during OER cycles increases faster than that of Ru. HRTEM images in Supplementary Fig. 18 reveal an evident loss of crystallinity of used $\mathrm{SrRuO}_{3}$.

Representative TEM and HRTEM/DDP images of $\mathrm{Sr}_{0.90} \mathrm{Na}_{0.10} \mathrm{RuO}_{3}$ are shown in Fig. $4 \mathrm{a}, \mathrm{b}$, respectively. The sample consists of particles of $\sim 2.8( \pm 0.5) \mu \mathrm{m}$ with perovskite structure; see DDP (inset of Fig. $4 \mathrm{~b}$ and SAED in Supplementary Fig. 4). STEM-EDX mapping (Fig. 4c) reveals the homogeneous 
a

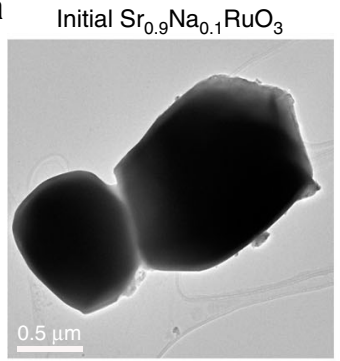

b

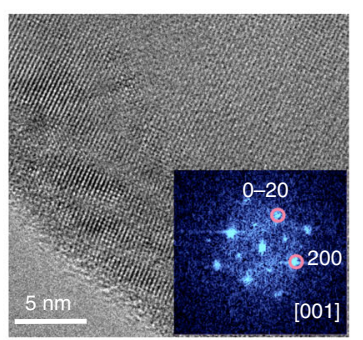

C

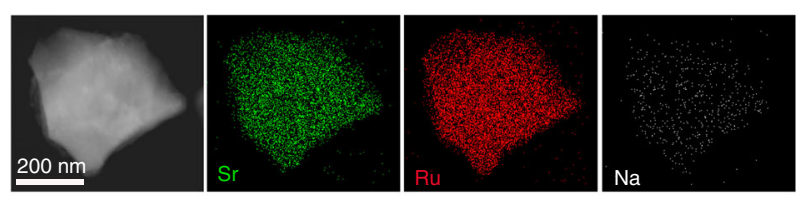

d $\mathrm{Sr}_{0.9} \mathrm{Na}_{0.1} \mathrm{RuO}_{3} 20$ cycles
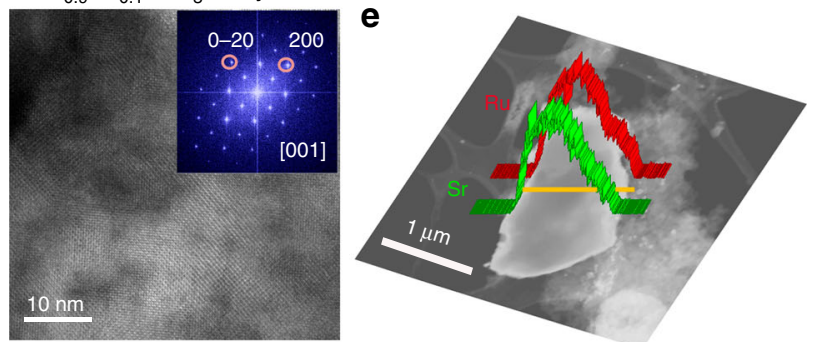

$\mathbf{f}$

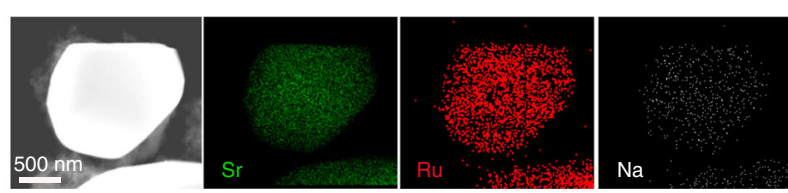

Fig. 4 Evolution of $\mathrm{Sr}_{0.90} \mathrm{Na}_{0.10} \mathrm{RuO}_{3}$ during OER. a TEM, b HRTEM/DDP, and $\mathbf{c}$ STEM-EDX mapping of $\mathrm{Sr}_{0.90} \mathrm{Na}_{0.10} \mathrm{RuO}_{3}$ before the OER reaction. d HRTEM/DDP images, e STEM-HAADF micrographs showing Ru and $\mathrm{Sr}$ line scan profiles and $\mathbf{f} \mathrm{STEM}-\mathrm{EDX}$ mapping of $\mathrm{Sr}_{0.90} \mathrm{Na}_{0.10} \mathrm{RuO}_{3}$ after 20 OER cycles

distribution of $\mathrm{Sr}, \mathrm{Ru}$, and $\mathrm{Na}$ in the perovskite. Figure $4 \mathrm{~d}$ shows a representative HRTEM/DDP image for used $\mathrm{Sr}_{0.90} \mathrm{Na}_{0.10} \mathrm{RuO}_{3}$. Contrary to $\mathrm{SrRuO}_{3}$, used $\mathrm{Sr}_{0.90} \mathrm{Na}_{0.10} \mathrm{RuO}_{3}$ still presents the perovskite structure (inset of Fig. 4d). As shown in Fig. 4e, the size and $\mathrm{Sr} / \mathrm{Ru}$ atomic ratio $(\sim 0.95)$ of used $\mathrm{Sr}_{0.90} \mathrm{Na}_{0.10} \mathrm{RuO}_{3}$ is similar to that of the fresh one. STEM-EDX mapping in Fig. $4 \mathrm{f}$ shows a homogeneous distribution of $\mathrm{Sr}, \mathrm{Ru}$, and $\mathrm{Na}$ in the used sample. These observations clearly indicate that neither the composition nor the structure of $\mathrm{Sr}_{0.90} \mathrm{Na}_{0.10} \mathrm{RuO}_{3}$ are affected after 20 cycles in the OER. HRTEM/DDP images (Supplementary Fig. 19) also reveal the high crystallinity of used $\mathrm{Sr}_{0.90} \mathrm{Na}_{0.10} \mathrm{RuO}_{3}$. However, note that the incipient formation of $\mathrm{RuO}_{x}$ is evidenced in the FFT filtered image shown in Supplementary Fig. 19b. Again, this observation is in good agreement with the ICP results shown in Supplementary Fig. 17b revealing small concentrations of $\mathrm{Sr}$ and $\mathrm{Ru}$ in the electrolyte after the OER, significantly lower than those found for $\mathrm{SrRuO}_{3}$. In fact, Supplementary Fig. 17b confirms that the Na-doped perovskite is more stable than $\mathrm{SrRuO}_{3}$ during the OER in acid electrolyte.

The structure of the used samples (20 cycles in the OER) has also been studied by XRD and XAS. The x-ray diffractograms of the fresh and used samples are similar and only show diffraction lines for the perovskite phase (Supplementary Fig. 20). The analysis of the $\mathrm{Ru}$ K-edge of fresh and used $\mathrm{SrRuO}_{3}$ and $\mathrm{Sr}_{0.90} \mathrm{Na}_{0.10} \mathrm{RuO}_{3}$ are shown in Fig. 5 and Supplementary Fig. 21.
The intensity of the FT-EXAFS signals of the used $\mathrm{SrRuO}_{3}$ sample is significantly lower than that of the fresh one, especially for the higher shells (Fig. 5a). This result reveals severe degradation (loss of crystallinity) of the $\mathrm{SrRuO}_{3}$ structure after the OER. Conversely, the FT-EXAFS signals of both fresh and used $\mathrm{Sr}_{0.90} \mathrm{Na}_{0.10} \mathrm{RuO}_{3}$ are similar (Fig. 5b), indicating that the perovskite structure remains stable during the OER. It is possible to estimate the composition of the used samples by a linear combination fit on the EXAFS signals of the fresh perovskites and $\mathrm{RuO}_{2}$. An approximate ratio of $20: 80 \mathrm{SrRuO}_{3}: \mathrm{RuO}_{2}$ is obtained for $\mathrm{SrRuO}_{3}$ (Supplementary Fig. 21c) being of 80:20 $\mathrm{Sr}_{0.90} \mathrm{Na}_{0.10} \mathrm{RuO}_{3}: \mathrm{RuO}_{2}$ for the Na-doped one (Supplementary Fig. 21d). These results are in excellent agreement with the microscopy results, and indicate that $\mathrm{Na}$ doping enhances the structural stability (and hence durability) of the perovskites during the OER. These conclusions also result from the evolution of the pre-edge features of the XANES Ru K-edge and the decrease in the white line (Supplementary Fig. 21a).

Finally, the surface composition of the fresh and used perovskites was analyzed by XPS. Figures $5 \mathrm{c}$, d depict the spectra of the Sr $3 \mathrm{~d}$ core-level regions of the fresh and used samples. The two $\mathrm{Sr} 3 \mathrm{~d}$ doublets are associated to carbonate (high binging energy) and Sr-O-M (lower binding energy) moieties. According to Supplementary Table 8 , the surface atomic $\mathrm{Ru} / \mathrm{Sr}$ ratio of both $\mathrm{SrRuO}_{3}$ and $\mathrm{Sr}_{0.90} \mathrm{Na}_{0.10} \mathrm{RuO}_{3}$ increases after the OER. Nevertheless, $\mathrm{Ru}$ enrichment is more pronounced in $\mathrm{SrRuO}_{3}$ (2.7) than in $\mathrm{Sr}_{0.90} \mathrm{Na}_{0.10} \mathrm{RuO}_{3}$ (1.8) indicating a more severe decomposition of $\mathrm{SrRuO}_{3}$.

The results above clearly indicate that $\mathrm{Sr}$ dissolves from the perovskite structure during the OER, especially from $\mathrm{SrRuO}_{3}$. Upon Sr dissolution, the perovskite structure becomes ill-defined, as observed by TEM and XAS. At some point, Ru segregates from the perovskite and forms nanosized $\mathrm{RuO}_{x}$ phases, which in some cases are deposited at the surface of the perovskites, but are mostly found as isolated particles (Supplementary Fig. 18). As predicted by DFT (Fig. 2c), the collapse of the perovskite and the formation of $\mathrm{RuO}_{x}$ lead to a significant loss in OER activity. The higher durability of $\mathrm{Na}$-doped samples is due to their higher structural stability and lower dissolution rates of $\mathrm{Sr}$ and $\mathrm{Ru}$ compared with $\mathrm{SrRuO}_{3}$, not to the formation of different phases during the OER. Several features can explain the enhanced durability of $\mathrm{Na}$-doped perovskites. On the one hand, it is known that $\mathrm{Ru}$ centers oxidize to $\mathrm{Ru}^{>4+}$ during potential excursions above $\sim 1.4 \mathrm{~V}^{45}$. These highly oxidized $\mathrm{Ru}$ atoms are not stable within undoped $\mathrm{SrRuO}_{3}{ }^{9}$. Na incorporation permits the stabilization of $\mathrm{Ru}^{>4+}$ ions within the lattice, resulting in versatile $\mathrm{Ru}$ catalytic centers that can easily increase or decrease their charge depending on the adsorbates, which is advantageous for the OER. Our results show that $\mathrm{Na}$ incorporation results in less distorted $\mathrm{RuO}_{6}$ octahedra and higher durability. This observation is in line with previous reports indicating that less distorted structures are more susceptible to suffer structural variations without being destroyed when subjected to voltage changes ${ }^{6}$. Finally, DFT calculations indicate that (i) the surface energies of $\mathrm{Sr}_{1-x} \mathrm{Na}_{x} \mathrm{RuO}_{3}$ are considerably lower compared with $\mathrm{SrRuO}_{3}$; (ii) the dissolution potentials of the cations in the A site of the perovskites are shifted toward more positive values in presence of $\mathrm{Na}$; and (iii) the stability at low $\mathrm{pH}$ is also enhanced upon $\mathrm{Na}$ doping. Such observations, described in detail in the Supplementary Note 10 , attest to more stable perovskite structures upon doping.

To summarize and conclude, we have synthesized a series of active catalysts $\left(\mathrm{Sr}_{1-x} \mathrm{Na}_{x} \mathrm{RuO}_{3}\right)$ for the OER in acid media with extraordinary features. The measured activities are comparable to or surpass those of other remarkable OER catalysts in the literature. $\mathrm{Na}$ incorporation in the lattice also grants these compounds high electrochemical and structural stability, so as to 

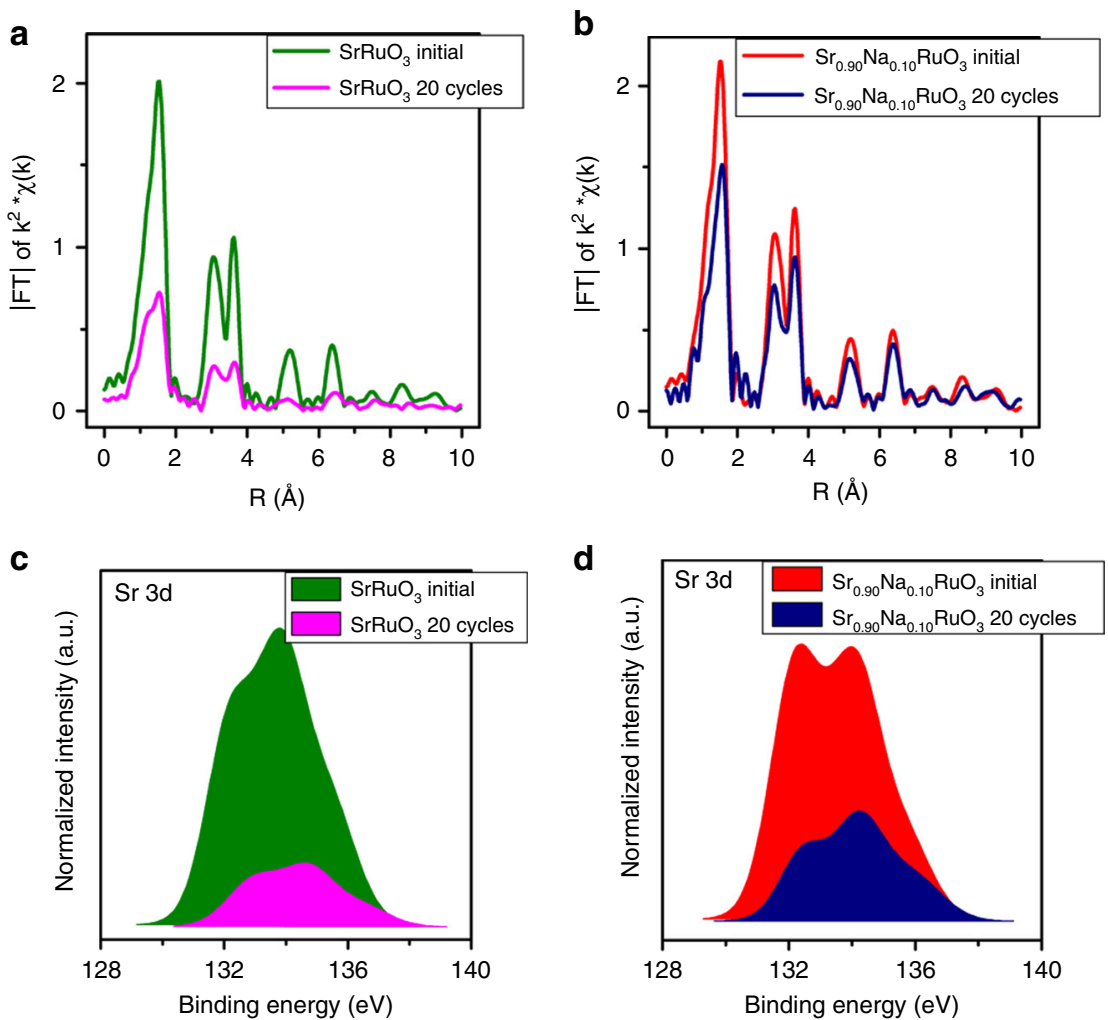

Fig. 5 XAS and XPS of fresh and cycled samples. a Fourier transform from Ru K-edge EXAFS signal before and after OER of $\mathrm{SrRuO}_{3}$ and $\mathbf{b}$ of $\mathrm{Sr}_{0.90} \mathrm{Na}_{0.10} \mathrm{RuO}_{3}$. c Sr-3d core-level region before and after OER of $\mathrm{SrRuO}_{3}$ and $\mathbf{d}$ of $\mathrm{Sr}_{0.90} \mathrm{Na}_{0.10} \mathrm{RuO}_{3}$. The intensity of the $\mathrm{Sr}$ peaks in the used samples is normalized to the intensity of $\mathrm{Sr}$ in the fresh samples

keep up to $85 \%$ of their initial activity after 20 cycles. Na locally changes the oxidation state of $\mathrm{Ru}$ from +4 to +5 , resulting in a convenient weakening of the adsorption energies of the OER intermediates, because $\mathrm{SrRuO}_{3}$ binds those too strongly. Our conclusions could help in guiding future research in several ways: (a) other monovalent cations such as $\mathrm{Li}^{+}, \mathrm{K}^{+}$, and $\mathrm{Cs}^{+}$can be tested to ascertain whether they also enhance the activity and/or the stability. (b) If $\mathrm{Ru}^{5+}$ sites are instrumental for the enhancement of $\mathrm{SrRuO}_{3}$, then B-site doping with e.g., trivalent cations might as well enhance the activity. (c) Since $\mathrm{Sr}_{0.875} \mathrm{Na}_{0.125} \mathrm{RuO}_{3}$ is the most active compound in Fig. $2 \mathrm{c}$, we used the ESSI to determine that its activity can be further optimized if the ${ }^{\star} \mathrm{OH}$ binding energy is strengthened by $-0.16 \mathrm{eV}$. This is an interesting hypothesis to be verified experimentally in subsequent studies.

\section{Methods}

Synthesis. $\mathrm{Sr}_{1-x} \mathrm{Na}_{x} \mathrm{RuO}_{3}(x=0.00,0.05,0.10)$ perovskites were synthesized in polycrystalline form by a wet-chemistry procedure to obtain very reactive precursors and reduce the final synthesis temperature. Stoichiometric amounts of $\mathrm{Sr}$ $\left(\mathrm{NO}_{3}\right)_{2}$ (Sigma Aldrich $99.99 \%$ trace metals basis), $\mathrm{Na}_{2} \mathrm{CO}_{3}$ anhydrous (Sigma Aldrich 99.999\% trace metals basis), and $\mathrm{RuO}_{2}$ (Sigma Aldrich 99.9\% trace metals basis) were dissolved in $150 \mathrm{~mL}$ of $0.1 \mathrm{M}$ citric acid (Sigma Aldrich assay $\geq 99.5 \%$ ) and $20 \mathrm{~mL}$ of nitric acid (Panreac 65\%), to ensure complete dissolution of the starting materials. We added $5 \%$ excess of $\mathrm{Na}_{2} \mathrm{CO}_{3}$ to compensate the possible partial evaporation at high temperatures. The mixture was stirred at $\sim 120^{\circ} \mathrm{C}$ until complete evaporation, leading to the formation of resins containing a homogeneous distribution of the metal cations. The resins were dried afterwards at $500^{\circ}$ $\mathrm{C}$ for $12 \mathrm{~h}$, to eliminate organic material and nitrates. Finally, the samples were subjected to different temperatures in air during $12 \mathrm{~h}: 800^{\circ} \mathrm{C}$ for $x=0.00,900^{\circ} \mathrm{C}$ for $x=0.05$ and $1000^{\circ} \mathrm{C}$ for $x=0.10$. If $\mathrm{SrRuO}_{3}$ is calcined at higher temperatures, other competitive phases appear.
Specimens for analysis were subjected to acid digestion in a mixture of $3 \mathrm{~mL}$ of $\mathrm{HNO}_{3}, 2 \mathrm{~mL} \mathrm{HCl}, 3 \mathrm{~mL} \mathrm{HF}$, and $3 \mathrm{~mL} \mathrm{H}_{3} \mathrm{PO}_{4}$, in a pressurized microwave.

Powder X-ray diffraction (XRD). The phases and their purity were determined by $\mathrm{XRD}$ in Bragg-Brentano reflection geometry with $\mathrm{CuK}_{\alpha}$ radiation $(\lambda=1.5418 \AA)$.

Powder neutron diffraction (PND). PND was carried out in the high-resolution powder diffractometer D2B at ILL (Grenoble, France). The data were collected at room temperature and $\lambda=1.594 \AA$. For the refinement of the crystal structures, we used the Rietveld method and the Fullprof crystallographic program ${ }^{46,47}$. The function selected to generate the diffraction peaks shape was pseudo-Voigt. The parameters refined in the final run were the scale factor, linear interpolation between a set of background points, zero-point error, pseudo-Voigt parameters, positional coordinates, isotropic thermal factors an occupancy factors.

Transmission electron microscopy (TEM). TEM data was recorded on a JEOL 2100 field emission gun transmission electron microscope operating at $200 \mathrm{kV}$ and equipped with an EDX spectrometer Oxford INCA Energy 2000 system. Specimens were prepared by depositing small portions of the samples on top of a $\mathrm{Cu}$ grid supporting a lacey carbon film. Deposition was achieved by preparing a suspension of the material in ethanol.

BET method. The measurements were performed in a Micromeritics ASAP 2000 apparatus. Surface areas were evaluated by purging with nitrogen the samples within the relative pressure range $P / P_{0}=0.05-0.30$. The amount of adsorbed nitrogen is related to the total surface area of the samples. The volume of gas adsorbed on the surface is measured at $-196^{\circ} \mathrm{C}$ (nitrogen boiling point). The samples are finally degassed at $140^{\circ} \mathrm{C}$ under vacuum for $24 \mathrm{~h}$. Specific areas were calculated by applying the BET method.

X-Ray absorption spectroscopy (XAS). XAS measurements were performed at room temperature at Diamond Light Source (UK) on the B18 and I10 beamlines ${ }^{48}$. In the case of 110 measurements, data were collected at Na K-edge $(E=1070.8 \mathrm{eV})$ and $\mathrm{Ru} \mathrm{M}_{2,3}$-edge $(E=461$ and $483 \mathrm{eV})$ in fluorescence mode with a photodiode sited to measure by back-scattering geometry. The Sr L3 and L2-edges appear at the half energy ( $1940 \mathrm{eV}$ and $2007 \mathrm{eV}$, respectively) as the undulator second harmonic is mostly absorbed but it partially passes through the monochromator at the energy of the first harmonic as a contamination. On the B18 beamline, data were collected 
at Ru K-edge $(E=22117 \mathrm{eV})$ in the transmission mode using a double crystal Sil11 monochromator and Pt-coated branch. Data treatment was performed with the ATHENA software ${ }^{49}$ and XANES simulations were performed with the FEFF 8.4 $\operatorname{code}^{50}$.

X-Ray photoemission spectroscopy (XPS). X-ray photoelectron spectra (XPS) were acquired with a VG ESCALAB $200 \mathrm{R}$ at a pass energy of $50 \mathrm{eV}$ using a $\mathrm{Mg} \mathrm{Ka}$ $\mathrm{X}$-ray source. The kinetic energies of the photoelectrons were measured using a hemispherical electron analyzer working in the constant-pass energy mode. The background pressure in the analysis chamber was kept below $3 \times 10^{-8} \mathrm{mbar}$ during data acquisition. At least 200 scans were collected in increments of $0.1 \mathrm{eV}$ with dwell times of $50 \mathrm{~ms}$ in order to increase the signal-to-noise ratio. The binding energies $( \pm 0.2 \mathrm{eV})$ were determined by setting the $\mathrm{C} 1$ s peak at $284.8 \mathrm{eV}$.

Electrochemical characterization. The electrochemical performance was tested in a computer-controlled Autolab PGstat $302 \mathrm{~N}$ potentiostat/galvanostat. A standard three-compartment glass cell and a rotating disk electrode (RDE) (Pine Research Instruments) were used. A graphite rod and a homemade Reversible Hydrogen Electrode (RHE) were used as counter and reference electrodes, respectively. $\mathrm{Sr}_{1}$ ${ }_{-} \mathrm{Na}_{x} \mathrm{RuO}_{3}$ samples were deposited on the electrode as inks. The powdered samples were mixed in a 5:1 mass ratio with carbon black (Vulcan-XC-72R) to improve the electrical conductivity. Then the solvents were added, Tetrahydrofuran (THF) and Nafion, to yield final concentrations of $5 \mathrm{mg}_{\text {oxide }} \mathrm{mL}^{-1}$ ink, $1 \mathrm{mg}_{\text {carbon }}$ $\mathrm{mL}^{-1}{ }_{\text {ink }}, 0.03 \mathrm{~mL}_{\text {Nafion }} \mathrm{mL}^{-1}$ ink, and $0.97 \mathrm{~mL}_{\mathrm{THF}} \mathrm{mL}^{-1}$ ink. We sonicated the ink with an Ultrasonic Processor UP50H (Hielscher) and dispersed $20 \mu \mathrm{L}$ of ink onto a glassy carbon electrode $\left(0.196 \mathrm{~cm}^{2}\right.$ area), with a final loading of catalyst on the electrode of $0.1 \mathrm{mg}$. We performed cyclic voltammetry between $1.1 \mathrm{~V}$ and $1.5 \mathrm{~V}$ or $1.1 \mathrm{~V}$ and $1.7 \mathrm{~V}$ at $10 \mathrm{mV} / \mathrm{s}$ and $1 \mathrm{mV} / \mathrm{s}$. The measurements were corrected under $\mathrm{O}_{2}$ saturated electrolyte to assure the $\mathrm{O}_{2} / \mathrm{H}_{2} \mathrm{O}$ equilibrium at $1.23 \mathrm{~V}$, and with an electrode rotation of $1600 \mathrm{rpm}$. The OER kinetic curves were capacitance-corrected by taking the average of the anodic and cathodic curves. The curves were also iRcorrected using the formula $\mathrm{E}-i R_{\text {corrected }}=\mathrm{E}_{\text {applied }}-i R$, where $i$ is the current and $R$ is the ohmic electrolyte resistance $(R \sim 29 \Omega)$ obtained from Electrical Impedance Spectroscopy (EIS) at open voltage. The OER electrocatalytic measurement methodology follows the one established by Shao-Horn and coworkers ${ }^{7,23}$. As stated above, we used a catalyst loading of $0.1 \mathrm{mg}$, the same reported in previous works. Such high loading could result in film diffusion resistance that prevents the determination of kinetic parameters from non-corrected K-L analyses ${ }^{51}$. However, the absence of mass transfer effects has been confirmed by conducting the OER at different scan and rotation rates, and by using different catalyst loadings, as detailed in Supplementary Note 15 and Supplementary Fig. 22. We have measured catalytic activity and durability at least five times for each catalyst. Errors are reported as relative standard deviation (RSD).

Computational methods. The spin-unrestricted DFT calculations of $\mathrm{Sr}_{X} \mathrm{Na}_{1}$ ${ }_{-} \mathrm{RuO}_{3}$ were performed with VASP ${ }^{52}$, using the RPBE exchange-correlation functional ${ }^{53}$, the projector augmented wave (PAW) method ${ }^{54}$, and Dudarev's DFT $+\mathrm{U}$ formalism ${ }^{55}$. The simulated slabs were 4-layer thick: the atoms in the two topmost layers and the adsorbates could move in all directions, whereas those in the two bottommost layers were fixed at the converged bulk distances. The relaxations were performed with the conjugate-gradient scheme, using as convergence criterion for the ionic loops a maximal force on any atom of $0.05 \mathrm{eV} \AA^{-1}$. We used $2 \times 2(001)$ perovskite slabs, which contained eight $\mathrm{SrRuO}_{3}$ formula units. When one of the Sr atoms was replaced by $\mathrm{Na}$, the slab was $\mathrm{Sr}_{7} \mathrm{Na}_{1} \mathrm{Ru}_{8} \mathrm{O}_{24}$, equivalent to $\mathrm{Sr}_{0.875} \mathrm{Na}_{0.125} \mathrm{RuO}_{3}$. We used a $4 \times 4 \times 1$ k-point mesh and a planewave cutoff of $400 \mathrm{eV}$ to ensure convergence of the adsorption energies within 0.05 $\mathrm{eV}$. We added $\sim 15 \AA$ of vacuum between periodical images in the $z$ direction and applied dipole corrections. We used Gaussian smearing with $\mathrm{k}_{\mathrm{B}} \mathrm{T}=0.2 \mathrm{eV}$, and extrapolated all energies to $0 \mathrm{~K}$. The gas-phase molecules $\left(\mathrm{H}_{2}, \mathrm{H}_{2} \mathrm{O}\right)$ were calculated in boxes of $15 \AA \times 15 \AA \times 15 \AA$, with $\mathrm{k}_{\mathrm{B}} \mathrm{T}=0.001 \mathrm{eV}$ and a $1 \times 1 \times 1$ k-point mesh. The value of $\mathrm{U}$ for $\mathrm{Ru}$ was $6.7 \mathrm{eV}$, found by Kitchin and coworkers for $\mathrm{RuO}_{2}$ through a linear-response methodology ${ }^{56}$. Such value is applicable to the Ru perovskites under study in view of the identical oxidation state of $\mathrm{Ru}(+4)$ in $\mathrm{RuO}_{2}$ and $\mathrm{SrRuO}_{3}$ and its similar coordination to oxygen in the form of octahedral $\mathrm{RuO}_{6}$ complexes. $\mathrm{RuO}_{2}$ in Fig. $2 \mathrm{c}$ was also calculated using the $\mathrm{DFT}+\mathrm{U}$ formalism with the same value of $U$. Supplementary Note 12 discusses the inaccuracies of standard DFT for the evaluation of adsorption energies of $\mathrm{RuO}_{2}(110)^{56}$ and plausible solutions ${ }^{56,57}$. The lattice constant found for $\mathrm{SrRuO}_{3}$ was $4.033 \AA$ and that of $\mathrm{Sr}_{0.875} \mathrm{Na}_{0.125} \mathrm{RuO}_{3}$ was $4.018 \AA$. As a first approximation, the former was used for all slab calculations. The free energies were approximated as: $\mathrm{G}=\mathrm{E}_{\mathrm{DFT}}+\mathrm{ZPE}-\mathrm{TS}$, where $\mathrm{E}_{\mathrm{DFT}}$ and ZPE are the DFT total and zero-point electronic energies, and TS are entropic contributions (only taken into account for gas-phase species). The TS corrections for $\mathrm{H}_{2}$ and $\mathrm{H}_{2} \mathrm{O}_{(\mathrm{l})}$ are 0.40 and $0.67 \mathrm{eV}^{58,59}$. The ZPEs for $\mathrm{H}_{2}, \mathrm{H}_{2} \mathrm{O}$, ${ }^{*} \mathrm{O}$, ${ }^{*} \mathrm{OH}$ and ${ }^{*} \mathrm{OOH}$ are $0.27,0.56,0.07,0.35$, and $0.40 \mathrm{eV}$, respectively. To describe the energetics of $\left(\mathrm{H}^{+}+\mathrm{e}^{-}\right)$and estimate overpotentials we used the computational hydrogen electrode ${ }^{58}$. The procedure for estimating the free energies of adsorption of the oxygen evolution intermediates, and details of the construction of the volcano plots making use of the scaling relations between the adsorption energies of the adsorbates (see Supplementary Note 11) appear elsewhere ${ }^{58,60,61}$. We included total adsorbate coverages of $0.5 \mathrm{ML}$ in all cases, so that ${ }^{*} \mathrm{O},{ }^{*} \mathrm{OH}$, and ${ }^{*} \mathrm{OOH}$ were co-adsorbed with ${ }^{\star} \mathrm{O}$. Such co-adsorption accounts for the fact that at OER potentials at least part of the active $\mathrm{Ru}$ sites are likely covered with ${ }^{*} \mathrm{O}$. The assessment of the ESSI is described in the Supplementary Note 11 and elsewhere ${ }^{39}$

\section{Data availability}

The data that support the findings of this study are available within the article and its Supplementary Information files. All other relevant data supporting the findings of this study are available from the corresponding authors upon request.

Received: 14 March 2018 Accepted: 27 March 2019

Published online: 03 May 2019

\section{References}

1. Steele, B. C. H. \& Heinzel, A. Materials for fuel-cell technologies. Nature 414, 345-352 (2001).

2. Wysokińska, Z. The "New" environmental policy of the European Union: a path to development of a circular economy and mitigation of the negative effects of climate change. Comp. Econ. Res. 19, 57-73 (2016).

3. Katsounaros, I., Cherevko, S., Zeradjanin, A. R. \& Mayrhofer, K. J. Oxygen electrochemistry as a cornerstone for sustainable energy conversion. Angew. Chem. Int. Ed. 53, 102-121 (2014).

4. Lee, Y., Suntivich, J., May, K. J., Perry, E. E. \& Shao-Horn, Y. Synthesis and activities of rutile $\mathrm{IrO} 2$ and $\mathrm{RuO} 2$ nanoparticles for oxygen evolution in acid and alkaline solutions. J. Phys. Chem. Lett. 3, 399-404 (2012).

5. Cherevko, S. et al. Oxygen and hydrogen evolution reactions on $\mathrm{Ru}, \mathrm{RuO} 2, \mathrm{Ir}$, and $\mathrm{IrO} 2$ thin film electrodes in acidic and alkaline electrolytes: A comparative study on activity and stability. Catal. Today 262, 170-180 (2016).

6. Hong, W. T. et al. Toward the rational design of non-precious transition metal oxides for oxygen electrocatalysis. Energy Environ. Sci. 8, 1404-1427 (2015).

7. Suntivich, J., May, K. J., Gasteiger, H. A., Goodenough, J. B. \& Shao-Horn, Y. A perovskite oxide optimized for oxygen evolution catalysis from molecular orbital principles. Science 334, 1383-1385 (2011).

8. Vojvodic, A. \& Norskov, J. K. Optimizing perovskites for the water-splitting reaction. Science 334, 1355-1356 (2011).

9. Tang, R. et al. Oxygen evolution reaction electrocatalysis on $\mathrm{SrIrO} 3$ grown using molecular beam epitaxy. J. Mater. Chem. A 4, 6831-6836 (2016).

10. Retuerto, M. et al. Structural effects of $\mathrm{LaNiO} 3$ as electrocatalyst for the oxygen reduction reaction. Appl. Catal. B 203, 363-371 (2017).

11. Chang, S. H. et al. Functional links between stability and reactivity of strontium ruthenate single crystals during oxygen evolution. Nat. Commun. 5, 4191 (2014)

12. Montiel, M., Hernández-Fernández, P., Fierro, J. L. G., Rojas, S. \& Ocón, P. Promotional effect of upper Ru oxides as methanol tolerant electrocatalyst for the oxygen reduction reaction. J. Power Sources 191, 280-288 (2009).

13. Kim, B.-J. et al. Unraveling thermodynamics, stability, and oxygen evolution activity of strontium ruthenium perovskite oxide. ACS Catal. 7, 3245-3256 (2017).

14. Diaz-Morales, O. et al. Iridium-based double perovskites for efficient water oxidation in acid media. Nat. Commun. 7, 12363 (2016).

15. Seitz, L. C. et al. A highly active and stable $\mathrm{IrOx} / \mathrm{SrIrO} 3$ catalyst for the oxygen evolution reaction. Science 353, 1011-1014 (2016).

16. Kibsgaard, J., Hellstern, T. R., Choi, S.-J., Reinecke, B. N. \& Jaramillo, T. F. Mesoporous ruthenium/ruthenium oxide thin films: active electrocatalysts for the oxygen evolution reaction. ChemElectroChem 4, 2480-2485 (2017).

17. Park, S.-A., Kim, K.-S. \& Kim, Y.-T. Electrochemically activated iridium oxide black as promising electrocatalyst having high activity and stability for oxygen evolution reaction. ACS Energy Lett. 3, 1110-1115 (2018).

18. Shannon, R. D. Revised effective ionic radii and systematic studies of interatomie distances in halides and chaleogenides. Acta Cryst. A32, 751-767 (1976).

19. Petr, T., Karel, K., Anke, W. \& Jiří, H. On the physical properties of Sr1 $-\mathrm{xNaxRuO} 3$ ( $\mathrm{x}=0-0.19)$. Solid State Sci. 12, 1112-1120 (2010).

20. Jeng, H. T., Lin, S. H. \& Hsue, C. S. Orbital ordering and Jahn-Teller distortion in Perovskite ruthenate SrRuO3. Phys. Rev. Lett. 97, 067002-067001 (2006).

21. Lee, S. et al. Large in-plane deformation of RuO6 octahedron and ferromagnetism of bulk SrRuO3. J. Phys. Condens. Matter 25, 465601 (2013).

22. Harano, T. et al. Role of doped $\mathrm{Ru}$ in coercivity-enhanced $\mathrm{La} 0.6 \mathrm{Sr} 0.4 \mathrm{MnO} 3$ thin film studied by x-ray magnetic circular dichroism. Appl. Phys. Lett. 102, 222404 (2013).

23. Suntivich, J., Gasteiger, H. A., Yabuuchi, N. \& Shao-Horn, Y. Electrocatalytic measurement methodology of oxide catalysts using a thin-film rotating disk electrode. J. Electrochem. Soc. 157, B1263 (2010). 
24. Jirkovský, J., Makarova, M. \& Krtil, P. Particle size dependence of oxygen evolution reaction on nanocrystalline $\mathrm{RuO} 2$ and $\mathrm{Ru} 0.8 \mathrm{Co} 0.2 \mathrm{O} 2-\mathrm{x}$. Electrochem. Commun. 8, 1417-1422 (2006).

25. Reier, T., Oezaslan, M. \& Strasser, P. Electrocatalytic oxygen evolution reaction (OER) on $\mathrm{Ru}, \mathrm{Ir}$, and Pt catalysts: a comparative study of nanoparticles and bulk materials. ACS Catal. 2, 1765-1772 (2012).

26. Jung, J.-I. et al. Optimizing nanoparticle perovskite for bifunctional oxygen electrocatalysis. Energy Environ. Sci. 9, 176-183 (2016).

27. Abbott, D. F. et al. Iridium oxide for the oxygen evolution reaction: correlation between particle size, morphology, and the surface hydroxo layer from operando XAS. Chem. Mater. 28, 6591-6604 (2016).

28. Matsumoto, Y., Yoneyama, H. \& Tamura, H. Influence of the nature of the conduction band of transition metal oxides on catalytic activity for oxygen reduction. J. Electroanal. Chem. 83, 237-243 (1977).

29. Matsumoto, Y. \& Sato, E. Electrocatalytic propeties of transition metal oxides for oxygen evolution reaction. Mater. Chem. Phys. I4, 397-426 (1986).

30. Stoerzinger, K. A., Qiao, L., Biegalski, M. D. \& Shao-Horn, Y. Orientationdependent oxygen evolution activities of rutile $\mathrm{IrO} 2$ and $\mathrm{RuO} 2$. J. Phys. Chem. Lett. 5, 1636-1641 (2014).

31. May, K. J. et al. Influence of oxygen evolution during water oxidation on the surface of perovskite oxide catalysts. J. Phys. Chem. Lett. 3, 3264-3270 (2012).

32. McCrory, C. C., Jung, S., Peters, J. C. \& Jaramillo, T. F. Benchmarking heterogeneous electrocatalysts for the oxygen evolution reaction. J. Am. Chem. Soc. 135, 16977-16987 (2013).

33. Trasatti, S. \& Petri, O. A. Real surface area measurements in electrochemistry. Pure Appl. Chern. 63, 71-734 (1991).

34. Zeradjanin, A. R., Ventosa, E., Bondarenko, A. S. \& Schuhmann, W. Evaluation of the catalytic performance of gas-evolving electrodes using local electrochemical noise measurements. ChemSusChem 5, 1905-1911 (2012)

35. Grimaud, A. et al. Double perovskites as a family of highly active catalysts for oxygen evolution in alkaline solution. Nat. Commun. 4, 2439 (2013).

36. Seh, Z. W. et al. Combining theory and experiment in electrocatalysis: insights into materials design. Science 355, eaad4998 (2017).

37. Medford, A. J. et al. Assessing the reliability of calculated catalytic ammonia synthesis rates. Science 345, 197-200 (2014).

38. Kuo, D. Y. et al. Influence of surface adsorption on the oxygen evolution reaction on IrO2(110). J. Am. Chem. Soc. 139, 3473-3479 (2017)

39. Govindarajan, N., García-Lastra, J. M., Meijer, E. J. \& Calle-Vallejo, F. Does the breaking of adsorption-energy scaling relations guarantee enhanced electrocatalysis? Curr. Opin. Electrochem. 8, 110-117 (2018).

40. Grimaud, A. et al. Activation of surface oxygen sites on an iridium-based model catalyst for the oxygen evolution reaction. Nat. Energy 2, 16189 (2016).

41. Burke, L. D. \& O'Meara, T. O. Oxygen electrode reaction. Part 2.-behaviour at ruthenium black electrodes. J. Chem. Soc., Faraday Trans. 68, 839-848 (1972).

42. Hodnik, N. et al. New Insights into corrosion of ruthenium and ruthenium oxide nanoparticles in acidic media. J. Phys. Chem. C. 119, 10140-10147 (2015).

43. Zeradjanin, A. R. et al. Rational design of the electrode morphology for oxygen evolution-enhancing the performance for catalytic water oxidation. RSC Adv. 4, 9579-9587 (2014).

44. Binninger, T. et al. Thermodynamic explanation of the universal correlation between oxygen evolution activity and corrosion of oxide catalysts. Sci. Rep. 5, 12167 (2015).

45. Goodenough, J. B., Manoharan, R. \& Paranthaman, M. Surface protonation and electrochemical activity of oxides in aqueous solution. J. Am. Chem. Soc. 112, 2016-2082 (1990).

46. Rietveld, H. M. A profile refinement method for nuclear and magnetic structures. J. Appl. Cryst. 2, 65-71 (1969).

47. Rodriguez Carvajal, J. Recent advances in magnetic-structure determination by neutron powder diffraction. Phys. B 192, 55-69 (1993).

48. Dent, A. J. et al. Performance of B18, the core EXAFS bending magnet beamline at diamond. J. Phys. 430, 012023 (2013).

49. Ravel, B. \& Newville, M. Athena, Artemis, Hephaestus: data analysis for X-ray absorption spectroscopy using IFEFFIT. J. Synchrotron Radiat. 12, 537-541 (2005).

50. Ankudinov, A. L., Ravel, B., Rehr, J. J. \& Conradson, S. D. Real-space multiplescattering calculation and interpretation of $\mathrm{x}$-ray-absorption near-edge structure. Phys. Rev. B 52, 7565 (1998)

51. Paulus, U. A., Schmidt, T. J., Gasteiger, H. A. \& Behm, R. J. Oxygen reduction on a high-surface area Pt/Vulcan carbon catalyst: a thin-film rotating ringdisk electrode study. J. Electroanal. Chem. 495, 134-145 (2001).

52. Kresse, G. \& Furthmüller, J. Efficient iterative schemes for ab initio total-energy calculations using a plane-wave basis set. Phys. Rev. B 54, 11169-11186 (1996).

53. Hammer, B., Hansen, L. B. \& Nørskov, J. K. Improved adsorption energetics within density-functional theory using revised Perdew-Burke-Ernzerhof functionals. Phys. Rev. B 59, 7413-7421 (1999).

54. Vanderbilt, D. Soft self-consistent pseudopotentials in a generalized eigenvalue formalism. Phys. Rev. B 41, 7892-7895 (1990).
55. Dudarev, S. L., Botton, G. A., Savrasov, S. Y., Humphreys, C. J. \& Sutton, A. P. Electron-energy-loss spectra and the structural stability of nickel oxide: an LSDA + U study. Phys. Rev. B 57, 1505-1509 (1998).

56. $\mathrm{Xu}, \mathrm{Z}$., Rossmeisl, J. \& Kitchin, J. R. A linear response DFT $+\mathrm{U}$ study of trends in the oxygen evolution activity of transition metal rutile dioxides. $J$. Phys. Chem. C 119, 4827-4833 (2015).

57. Briquet, L. G. V., Sarwar, M., Mugo, J., Jones, G. \& Calle-Vallejo, F. A new type of scaling relations to assess the accuracy of computational predictions of catalytic activities applied to the oxygen evolution reaction. ChemCatChem $\mathbf{9}$, 1261-1268 (2017)

58. Calle-Vallejo, F. \& Koper, M. T. M. First-principles computational electrochemistry: achievements and challenges. Electrochim. Acta 84, 3-11 (2012).

59. Nørskov, J. K. et al. Origin of the overpotential for oxygen reduction at a fuelcell cathode. J. Phys. Chem. B 108, 17886-17892 (2004).

60. Man, I. C. et al. Universality in oxygen evolution electrocatalysis on oxide surfaces. ChemCatChem 3, 1159-1165 (2011).

61. Calle-Vallejo, F., Díaz-Morales, O. A., Kolb, M. J. \& Koper, M. T. M. Why is bulk thermochemistry a good descriptor for the electrocatalytic activity of transition metal oxides? ACS Catal. 5, 869-873 (2015).

\section{Acknowledgements}

This work was supported by the ENE2013-42322-R and ENE2016-77055-C3-3-R projects from the Spanish Ministry of Economy and Competitiveness (MINECO). M.R. thanks MINECO's Juan de la Cierva program for a grant (FPDI-2013-17582). F.C.V. thanks the Spanish MICIU for a Ramón y Cajal research contract (RYC-2015-18996) and financial support through the program "Units of Excellence María de Maeztu" (grant MDM-2017-0767). We thank G. Cibin for useful discussions on XAS data treatment and analysis from experiments on beamline B18 Diamond Light Source. We also thank A. Figueroa for helping with data acquisition on beamline I10 and discussions on data interpretation. We thank Diamond Light Source for access to beamlines B18 and I10 that contributed to the results presented here. We thank D. Arroyo and N. López for ICPOES analyses.

\section{Author contributions}

M.R. and S.R. conceived and developed the idea of the project; M.R., A.G., and A.E. prepared the samples; M.R., A.E., A.G., J.T., J.L.G.F., and M.A.P. made the electrochemical and physico-chemical characterization; L.P. obtained the electron microscopy measurements; F.C.V. performed the DFT calculations and discussion; P.F., D.G., and P. B. did the synchrotron X-ray absorption spectroscopy measurements and analysis; M.R. and M.T.F. collected the powder neutron diffraction data; M.R. refined the powder neutron diffraction data; M.R., F.C.V., and S.R. co-wrote the paper; all authors commented on the manuscript; S.R. coordinated the project.

\section{Additional information}

Supplementary Information accompanies this paper at https://doi.org/10.1038/s41467019-09791-w.

Competing interests: The authors declare no competing interests.

Reprints and permission information is available online at http://npg.nature.com/ reprintsandpermissions/

Journal peer review information: Nature Communications would like to thank the anonymous reviewer(s) for their contribution to the peer review of this work

Publisher's note: Springer Nature remains neutral with regard to jurisdictional claims in published maps and institutional affiliations.

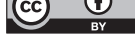

Open Access This article is licensed under a Creative Commons Attribution 4.0 International License, which permits use, sharing, adaptation, distribution and reproduction in any medium or format, as long as you give appropriate credit to the original author(s) and the source, provide a link to the Creative Commons license, and indicate if changes were made. The images or other third party material in this article are included in the article's Creative Commons license, unless indicated otherwise in a credit line to the material. If material is not included in the article's Creative Commons license and your intended use is not permitted by statutory regulation or exceeds the permitted use, you will need to obtain permission directly from the copyright holder. To view a copy of this license, visit http://creativecommons.org/ licenses/by/4.0/.

(C) The Author(s) 2019 